\title{
Climate change and intergenerational equity: Revisiting the uniform taxation principle on carbon energy inputs
}

\author{
Maria Elisa Belfiori*
}

May 1, 2018

\begin{abstract}
This paper presents a neoclassical growth model with three energy sectors and a climate externality. Energy is used in the production of the final consumption good. The energy sectors differ on the exhaustibility of the energy resource. Oil is an exhaustible resource, coal is an abundant resource, and a green energy sector uses labor. Oil and coal use increases the stock of carbon in the atmosphere, which generates a climate externality. Standard Pigouvian taxation prescribes that a uniform tax on all carbon energy inputs is optimal. This uniform tax must be equal to the social cost of carbon because this is the externality that the usage of these inputs generates. I consider a policymaker who cares about future generations and may discount the future less than the individuals in the economy. This paper's main theoretical result is that the uniform taxation rule does not carry over to an economy with a low social discount rate. In particular, the optimal carbon tax on oil does not equal the optimal carbon tax on coal. Moreover, while the optimal tax on coal equals the social cost of carbon, the optimal carbon tax on oil follows a more general formula.
\end{abstract}

Keywords: Climate; Environmental Equity; Optimal Taxation; Environmental Taxes and Subsidies.

JEL: Q54; Q56; H21; H23

*Departamento de Investigación, Facultad de Ciencias Económicas, Pontificia Universidad Católica Argentina, Av. Alicia Moreau de Justo 1400. Buenos Aires, C1107AFB, Argentina. elisa_belfiori@uca.edu.ar 


\section{Introduction}

Carbon emissions released into the atmosphere have a mean lifetime of about 300 years, which implies that carbon emissions are an intergenerational externality. This paper studies the optimal taxation of alternative energy sources (i.e., coal, oil, natural gas, renewables) in an economy that captures both the externality and the intergenerational aspect of climate change.

Concerns about intergenerational equity have sparked a heated debate over the choice of the social discount rate in macro-climate models. Stern (2008) argues for a low discount rate based on a desire for intergenerational equity. Nordhaus (2007), Weitzman (2007), and many others criticize this point of view. They say that the discount rate should be consistent with market returns. This paper incorporates a social welfare function that assigns Pareto weights to the welfare of future generation, which maps onto low social discounting. Thus, the relevant question is what the appropriate Pareto weights are - not what the proper social discount rate is. In that sense, there is also no right or wrong answer.

Furthermore, standard Pigouvian taxation prescribes that a uniform tax on all carbon energy inputs is optimal. This uniform tax must be equal to the social cost of carbon (SCC) because this is the externality that the usage of these inputs generates. This paper's main theoretical result is that the uniform taxation principle does not carry over to an economy with a low social discount rate. In particular, the paper shows that the optimal carbon tax on oil does not equal the optimal carbon tax on coal. Therefore, creating a ton of carbon by burning oil is not equivalent to creating a ton of carbon by using coal, even if both had the same effect on the aggregate externality. Moreover, while the optimal tax on coal equals the SCC, the optimal carbon tax on oil follows a more general formula. I theoretically characterize the optimal tax rates and show that both, the SCC and the social and private discount rates, play a role in the optimal tax on oil.

This paper develops its argument in a neoclassical growth model with three energy sectors and a climate externality. The production of the final consumption good uses energy inputs. The energy sectors differ on the exhaustibility of the energy resource. Oil is an exhaustible resource; coal is an abundant resource, and a green energy sector uses labor. Oil and coal use increases the stock of carbon in the atmosphere, which generates the climate externality.

This paper assumes that coal and oil have the same effect on the aggregate externality. However, coal emits more CO2 than oil per unit of energy. van der Ploeg and Withagen 
(2012) show that, if one takes into account that coal is dirtier, it is optimal to use more oil and less coal. Similarly, Golosov et al. (2014) find that the welfare gains from the introduction of an optimal carbon tax come from the efficient use of coal, and not so much of oil. Even though oil is used up too quickly in the laissez-faire economy, the inefficient use of coal leads to substantial welfare losses because the stock of coal is much larger and, therefore, leads to significant global warming. Thus, both papers conclude that coal is the real threat to climate change. In this paper, I argue that this conclusion may not carry over to climate models with social discounting. In particular, achieving intergenerational equity as a climate goal depends much more on the efficient use of oil reserves, and not so much of coal. The reason is that oil is exhaustible, and there are substantial welfare losses from passing on too little oil to future generations.

This paper is closely related to von Below (2012), Belfiori (2017) and Barrage (2018), who study the implications of social discounting on the design of optimal carbon taxes. Like von Below (2012), I also find that the social and private discount rates appear as an extra term in the optimal carbon tax formula, and that a capital income subsidy is optimal. The optimality of the capital income subsidy is also characterized in Barrage (2018). However, this paper differs from both von Below (2012) and Barrage (2018) in that I derive the policy implications of social discounting on alternative energy sources such as coal, oil and green energy. This paper borrows the approach to social discounting from Belfiori (2017). The main difference with that paper is that Belfiori (2017) considers oil as the only input in the production process and, therefore, it does not study the different policy implications of social discounting on alternative energy sources such as oil versus coal and renewable energy. This paper is also related to the literature on the optimal taxation of fossil fuels with a climate externality within a standard neoclassical macroeconomic framework, including Acemoglu et al. (2012), Barrage (2017), and Golosov et al. (2014). However, this paper differs from those papers because they do not formally study the interaction between social discounting and the optimal design of carbon policies. This paper also differs from Barrage (2017) in that I assume that the government has access to lump sum taxes. This paper relates to Belfiori (2015), Karp (Karp) and Gerlagh and Liski (2018) in that all of them focus on the interaction between social discounting and the design of optimal carbon policies. Like these papers, I also find that, with social discounting, the optimal carbon tax is not equal to the social cost of carbon. However, this paper differs from those in several aspects. First, this paper restricts attention to geometric discounting, and it does not contemplate inconsistency and 
commitment problems. Second, this paper focuses on how the exhaustibility nature of the energy resources have an impact on the optimal carbon tax when there is social discounting.

The remainder of the paper is organized as follows. Section 2 sets up the basic model. Section 3 introduces the concept of intergenerational climate equity. Section 4 characterizes the social optimum. Section 5 describes the market outcome and contains the main results of the paper. Section 6 provides some conclusions from the analysis. Finally, the Appendix includes all the mathematical proofs.

\section{Model}

Consider the following version of the economy in Golosov et al. (2014). Time is discrete and infinite, $t \in\{0, \ldots, \infty\}$. The economy is populated by a unit mass continuum of identical individuals. There is a single consumption good that is produced using capital, labor, and energy. The production function is given by

$$
\tilde{Y}_{t}=F\left(K_{t}, N_{0 t}, E_{t}\right)
$$

where $E_{t}$ is an energy composite. The energy components differ on the exhaustibility of the resource involved. In particular, I assume that there are three types of resources: an exhaustible resource $\left(E_{1}\right)$; an exhaustible but abundant resource $\left(E_{2}\right)$; and a renewable resource $\left(E_{3}\right)$. According to estimates of the world reserves, the ratio of coal reserves to production is about three times larger than the corresponding ratio for oil and gas. Therefore, I will refer to sector 2 as "coal" and to sector 1 as "oil", where oil means oil and natural gas throughout the paper. The energy composite, $E_{t}$, is defined as

$$
E_{t}=\left[\kappa_{1} E_{1 t}^{\rho}+\kappa_{2} E_{2 t}^{\rho}+\kappa_{3} E_{3 t}^{\rho}\right]^{1 / \rho}
$$

where $\sum_{i=1}^{3} \kappa_{i}=1$, and the parameter $\rho$ represents the elasticity of substitution between the energy components. According to the metastudy in Stern (2010), this elasticity is low at the macro level, and somehow larger at the industry level. The elasticity of substitution is higher between coal and gas, and lower for oil. The elasticity of substitution is also higher in power generation and lower in other uses such as transportation. The elasticity of substitution between the energy components does not affect the theoretical results in this paper, although it can be important quantitatively as shown in Golosov et al. (2014). 
The energy components are produced according to their own technology. Oil is an exhaustible resource, and it is costly to extract. At each point in time, oil use equals total oil extraction

$$
E_{1 t}=R_{t}-R_{t+1}
$$

for every period t. The extraction cost is stock-dependent and given by $g\left(R_{t}\right)$ where $\mathrm{g}$ is an increasing, convex, and differentiable cost function. Furthermore, the extraction cost is in units of the final consumption good. The economy starts with an initial stock of oil, $R_{0}$.

Coal is also finite, but it is assumed to be an abundant resource. Hence, there are no scarcity rents associated with coal use. Moreover, coal energy is produced using labor according to the function

$$
E_{2 t}=A_{2 t} N_{2 t}
$$

where $A_{2 t}$ is productivity in the coal sector.

Renewable energy production also uses labor and has sector-specific productivity given by $A_{3 t}$. Thus,

$$
E_{3 t}=A_{3 t} N_{3 t}
$$

The sub-index $t$ in the productivity parameter indicates the possibility of technical change. This change can be an improvement in the available technologies but can also reflect a slowdown in the development of new techniques. The technological change is exogenous.

Oil and coal use increases carbon in the atmosphere, $S_{t}$. In particular, carbon in atmosphere in every period t evolves according to

$$
S_{t+1}=(1-\gamma) S_{t}+E_{1 t}+E_{2 t}
$$

where $\gamma \in[0,1)$ is the natural rate of carbon reabsorption and the economy starts with a stock of carbon $S_{0}$. The stock of carbon in the atmosphere generates a climate externality that takes the form of an output loss. Thus, total output with the climate externality is given by

$$
Y_{t}=x\left(S_{t}\right) F\left(K_{t}, N_{0 t}, E_{t}\right)
$$

The damage function $x$ is decreasing, convex and twice differentiable with $\lim _{S \rightarrow 0} x(S)=1$ and $\lim _{S \rightarrow \infty} x(S)=0$.

Individuals derive utility from consumption and discount the future with the discount factor $\beta \in(0,1)$. Over time, individuals care about the value

$$
\sum_{t=0}^{\infty} \beta^{t} u\left(C_{t}\right)
$$


The utility function $u$ is increasing, concave and twice differentiable with $\lim _{c \rightarrow 0} u^{\prime}(c)=\infty$. Individuals consume, work and invest in capital. Capital depreciates at rate $\delta$ and evolves according to the law of motion

$$
K_{t+1}=(1-\delta) K_{t}+I_{t}
$$

The economy starts with an initial stock of capital $K_{0}$. The feasibility constraints in this economy are given by

$$
\begin{gathered}
C_{t}+K_{t+1}+g\left(R_{t}\right)=Y_{t}+(1-\delta) K_{t} \\
N_{t}=\sum_{i=0}^{3} N_{i}
\end{gathered}
$$

for every period t.

\section{$3 \quad$ Intergenerational climate equity}

When a representative infinitely lived individual inhabits the economy, it is natural to consider a social welfare function that coincides with the individual's welfare function in equation (8). That is, a planner or representative government represents the preferences of the voters (consumers) by sharing the same objective function with them. The assumption of an infinitely-lived individual is unrealistic, but it is widely used because it represents the idea of a dynasty. It can be quickly shown that an economy populated by a sequence of individuals, each of whom lives for one period and have one child, is equivalent to an economy populated by a single individual that lives forever.

In such a dynastic setup, the discount factor equals the altruistic weight that the parent puts on the child's welfare, and represents how much the parent cares for her child. Going back to the idea of the representative government, it is no longer evident that the social welfare function should coincide with the individual's welfare function in equation (8). Should the government only care about the well-being of the father, and let the father care for the child? Or should the government care about the child and future generations directly, despite the fact that the father might care for the child as well? This is a non-trivial question in climate economics because the parent's actions (i.e., the carbon emissions he generates using electricity, driving his car, and so on) will have long-lasting effects that will affect his child, his grandchild and many generations to come. It is crucial then that future generations are 
well taken care of and represented in the social welfare function that the current government uses to design climate policies.

In a dynastic economy like the one described above, the government can consider a more general utilitarian welfare function where a specific weight is attached to the welfare of each generation. Thus, the social welfare is the weighted sum of the welfare of each subsequent generation. In particular, the social welfare is

$$
\sum_{s=0}^{\infty} \alpha_{s}\left[\sum_{t=s}^{\infty} \beta^{t-s} U\left(C_{t}\right)\right]
$$

where $\left\{\alpha_{s}\right\}_{s=0}^{\infty}$ is an arbitrary weighting scheme across generations. An intergenerational choice is involved in the decision about the appropriate weighting scheme. This choice is normative in nature, and it is a comprehensive part of the climate policy design problem.

One option for the policymaker is to choose a degenerate weighting scheme where all the weight is on the current generation's welfare $\left(\alpha_{0}=1\right)$, and zero weight is attached to the future generation's welfare. Notice that, even in this case, the government cares about the future generation through the altruistic weight of the parents. The government cares "indirectly" about the child because it cares about the father, who cares about the child. This is one particular weighting scheme and, importantly, it is the one that will reflect the most impatient policymaker. As the government chooses to put some direct weight on the future generation's welfare, an infinite array of intergenerational choices open up. Each of these choices reflects a concern for intergenerational equity that will determine the policy decisions.

As shown by Bernheim (1989) and also Farhi and Werning (2007), a social welfare function that includes strictly positive weights on the welfare of future generations maps into a social welfare function where the government cares about the infinite stream of consumption of an infinitely lived individual, but discounts the future less than this individual. That is, the social discount rate is lower than the private discount rate ${ }^{1}$. Thus, I will consider a social planner who cares about the stream of consumption according to the following welfare function

$$
\sum_{t=0}^{\infty} \hat{\beta}^{t} u\left(C_{t}\right)
$$

\footnotetext{
${ }^{1}$ The social welfare weights must be geometric to ensure that the policy-design problem is time-consistent. That is, the weight on future generation's welfare is positive but decreases geometrically over time. See Belfiori (2017) for further discussion on this.
} 
with $\hat{\beta} \in(0,1)$ and $\hat{\beta}>\beta$. The social discount rate is lower than the private discount rate as a consequence of a social welfare criterion that attaches some weight to the welfare of future unborn generations.

\section{Optimal Allocation}

The socially optimal allocation is the path of consumption, labor, oil, capital and carbon level, $\left\{C_{t}^{*}, N_{0 t}^{*}, N_{2 t}^{*}, N_{3 t}^{*}, R_{t}^{*}, K_{t}^{*}, S_{t}^{*}\right\}_{t=0}^{\infty}$, that maximizes the social welfare function (13) subject to the carbon cycle (6), the resource constraints (10)-(11) together with (2)-(5), and the initial conditions $\left\{K_{0}, R_{0}, S_{0}\right\}$.

Let $\mu_{t}^{*}$ be the Lagrange multiplier on the carbon cycle constraint. The social cost of carbon can be obtained by iterating forward on the optimality condition of the carbon stock. In particular, the social cost of carbon is given by ${ }^{2}$

$$
\mu_{t}^{*}=-\sum_{j=0}^{\infty}[\hat{\beta}(1-\gamma)]^{j} \frac{u^{\prime}\left(c_{t+j}\right)}{u^{\prime}\left(c_{t}\right)} x^{\prime}\left(S_{t+j}\right) F(t+j)
$$

The social cost of carbon measures the value of the climate externality, which is given by the discounting sum of future output losses that will derive from a marginal increase in the current stock of carbon. The expression for the social cost of carbon is the expression obtained in similar economic environments like Golosov et al. (2014) and Barrage (2017). In fact, equation (14) simplifies even further if one assumes logarithmic utility and an exponential damage function of the form $x(S)=e^{-\varphi S}$. Under these assumptions, the social cost of carbon is equal to

$$
\mu_{t}^{*}=\sum_{j=0}^{\infty}[\hat{\beta}(1-\gamma)]^{j} \varphi \frac{c_{t}}{c_{t+j}} Y_{t+j}
$$

which collapses to an expression that only depends on parameters and output when the savings rate is constant. That is, as in Golosov et al. (2014), the social cost of carbon can then be written as

$$
\mu_{t}^{*}=Y_{t} \sum_{j=0}^{\infty}[\hat{\beta}(1-\gamma)]^{j} \varphi
$$

\footnotetext{
${ }^{2}$ To ease readability, I use the shortcut " $\mathrm{F}(\mathrm{t}+\mathrm{j})$ " to indicate the production function evaluated at time $\mathrm{t}+\mathrm{j}$.
} 
Because it will be useful to derive the results, I will define $\Lambda_{t}^{*}$ as the social cost of carbon expressed in units of the consumption good.

$$
\Lambda_{t}^{*} \equiv \frac{\mu_{t}^{*}}{u^{\prime}\left(C_{t}^{*}\right)}
$$

The socially optimal allocation is fully characterized by equation (14) together with two intra-temporal conditions, two inter-temporal conditions, a transversality condition for the capital stock and the feasibility constraints (10)-(11).

Given the assumptions on the production function, all three sources of energy are used in production. At the optimum, the marginal labor productivity must be equalized across sectors. Thus, the two intra-temporal conditions that characterize the optimal allocation are

$$
\begin{gathered}
x\left(S_{t}\right) F_{N_{0}}^{\prime}(t)=x\left(S_{t}\right) F_{N_{2}}^{\prime}(t)-\Lambda_{t}^{*} \\
x\left(S_{t}\right) F_{N_{0}}^{\prime}(t)=x\left(S_{t}\right) F_{N_{3}}^{\prime}(t)
\end{gathered}
$$

Because coal use increases atmospheric carbon, the marginal labor productivity in the coal sector is equal to the output increase from adding an extra worker net of the climate damages associated with this increase. For this reason, the social cost of carbon shows up in equation (18).

The first order conditions for consumption and oil imply that

$$
\hat{\beta} u^{\prime}\left(C_{t+1}\right)\left[x\left(S_{t+1}\right) F_{r}^{\prime}(t+1)-g^{\prime}\left(R_{t+1}\right)-\Lambda_{t+1}^{*}\right]=u^{\prime}\left(C_{t}\right)\left[x\left(S_{t}\right) F_{r}^{\prime}(t)-\Lambda_{t}^{*}\right]
$$

Equation (20) is a version of the Hotelling rule in this economy. It implies that the marginal benefit from extracting the exhaustible resource must be same across time. This benefit is given by the marginal increase in output obtained from an extra unit of oil, net of the associated climate damages and the increase in future extraction costs as the oil stock decreases. Because output tomorrow (and consumption) can be increased either by postponing extraction or by accumulating capital, a similar Euler equation holds for the capital stock:

$$
\hat{\beta} u^{\prime}\left(C_{t+1}\right) x\left(S_{t+1}\right) F_{k}^{\prime}(t+1)=u^{\prime}\left(C_{t}\right)
$$

Notice that the social cost of carbon does not show up in the Euler equation for capital because it is the energy use, and not production, what causes the increase in atmospheric carbon. Importantly, the future benefits from a marginal increase in the capital stock are 
evaluated in present value terms using the social discount rate. This is also true in (20). Finally, the capital stock must also satisfy the following transversality condition

$$
\lim _{t \rightarrow \infty} \hat{\beta}^{t} u^{\prime}\left(C_{t}^{*}\right) k_{t}=0
$$

Oil reserves and capital are the assets that allow the economy to transfer resources overtime. It follows that the optimal rate of return on both assets must be the same at all times to rule out any arbitrage opportunities. Otherwise, suppose that the return on capital is higher than the return on oil, it is optimal to burn oil and invest the proceeds at the market interest rate. This will push the market interest rate down until the return on both capital and oil are the same. In particular, equations (20) and (21) can also be combined in a non-arbitrage condition that is given by the following expression

$$
\frac{x\left(S_{t+1}\right) F_{r}^{\prime}(t+1)-g^{\prime}\left(R_{t+1}\right)-\Lambda_{t+1}^{*}}{x\left(S_{t}\right) F_{r}^{\prime}(t)-\Lambda_{t}^{*}}=x\left(S_{t+1}\right) F_{k}^{\prime}(t+1)
$$

To sum up, the socially optimal allocation is fully characterized by equations (10)-(11) and (18)-(22). The following section presents a decentralized environment that implements this optimal allocation with carbon taxes on oil and coal.

\section{Optimal energy taxes}

In the presence of a climate externality, a straightforward application of Pigouvian taxation principles calls for the introduction of carbon taxes on oil and coal, both equal to the social cost of the carbon externality. These carbon taxes make firms face the social cost of using energy and, hence, internalize the externality. In this section, I propose a decentralized environment with carbon taxes on coal, oil, renewable energy, and capital income. As usual, negative tax rates will indicate a subsidy. I will then use the optimal allocation to back out the optimal tax rates. I choose to start from a broad set of policy instruments - notice that all inputs in the economy are taxed - to find out later what tax rates are redundant and should be zero. The analysis does not include labor income taxes because optimal labor income taxes are zero in an economy with exogenous labor supply and no government financing needs.

There are 4 production units or "sectors" indexed by $j=0,1,2,3$. Sector 0 corresponds to the final consumption good sector, and the remaining three are the energy producers. A representative firm operates the technology (7) that produces the final consumption good. The firm hires labor at a wage $w_{t}$, rents capital from households at rate $r_{t}$, and buys energy 
inputs from the energy sectors at relative prices $p_{j t}$. The problem of the firm is to choose the path of capital, employment, and energy use, $\left\{K_{t}, N_{0 t}, E_{1 t}, E_{2 t}, E_{3 t}\right\}_{t=0}^{\infty}$, to maximize discounted profits given by

$$
\Pi_{0}=\sum_{t=0}^{\infty} q_{t}^{0}\left[x\left(S_{t}\right) F\left(K_{t}, N_{0 t}, E_{t}\right)-r_{t} K_{t}-w_{t} N_{0 t}-\sum_{j=1}^{3} p_{j t} E_{j t}\right]
$$

where $q_{t}^{0}$ is the Arrow-Debreu price of one unit of consumption in period $\mathrm{t}$ in terms of consumption in period zero, and $E_{t}$ is defined in (2).

A continuum of firms of mass one, or a representative firm, in the oil sector $(j=1)$ owns the stock of oil and faces a per-unit carbon tax $\tau_{1 t}$ on oil extraction. Extraction costs increase as the oil reserves decrease, and $R_{0}$ is the initial stock of oil. The problem of the firm is to choose a path of oil extraction $\left\{R_{t}\right\}_{t=0}^{\infty}$ to maximize discounted profits given by

$$
\Pi_{1}=\sum_{t=0}^{\infty} q_{t}^{0}\left[\left(p_{1 t}-\tau_{1 t}\right)\left(R_{t}-R_{t+1}\right)-g\left(R_{t}\right)\right]
$$

A continuum of firms of mass one, or a representative firm, in the coal sector $(\mathrm{j}=2)$ operates a linear technology given by (4) and faces a per-unit carbon tax $\tau_{2 t}$. The problem of the firm is to hire labor $\left\{N_{2 t}\right\}_{t=0}^{\infty}$ in order to maximize discounted profits given by

$$
\Pi_{2}=\sum_{t=0}^{\infty} q_{t}^{0}\left[\left(p_{2 t}-\tau_{2 t}\right) A_{2 t} N_{2 t}-w_{t} N_{2 t}\right]
$$

Finally, the representative firm in the green sector $(\mathrm{j}=3)$ operates the technology $(5)$ and faces a per-unit tax equal to $\tau_{3 t}$. Although it is natural to think about the tax on renewables as a subsidy, I define all instruments as taxes for consistency in the notation across energy sectors. As usual, a negative tax rate indicates a subsidy. The problem of the firm is to maximize discounted profits given by

$$
\Pi_{3}=\sum_{t=0}^{\infty} q_{t}^{0}\left[\left(p_{3 t}-\tau_{3 t}\right) A_{3 t} N_{3 t}-w_{t} N_{3 t}\right]
$$

There is a representative household who derives utility from the consumption of the single good in the economy, makes the capital investment decision, and owns the firms. As discussed before, the concept of a representative household can be thought of as a dynasty that lasts forever, and it is composed of a sequence of one-period lived individuals, each of whom has 
one child. Households face a capital income tax, and consume, work and save subject to the following present value budget constraint

$$
\sum_{t=0}^{\infty} q_{t}^{0}\left[C_{t}+K_{t+1}\right] \leq \sum_{t=0}^{\infty} q_{t}^{0}\left[\left(1-\tau_{t}^{k}\right) r_{t} K_{t}+w_{t} N_{t}+T_{t}\right]+\Pi
$$

where $\Pi=\sum_{j=0}^{3} \Pi_{j}$ are dividends from the firms, $T_{t}$ represents a lump sum rebate from the government, and $K_{0}$ is the initial stock of capital. The household's problem is to choose a sequence $\left\{C_{t}, K_{t}\right\}_{t=0}^{\infty}$ to maximize (8) subject to (28), taking prices and taxes as given.

A government collects carbon taxes and pays subsidies. Any surplus (or deficit) is rebated in a lump-sum transfer to households. The government budget constraint is given by

$$
\sum_{j=1}^{3} \tau_{j t} E_{j t}+\tau_{t}^{k} r_{t} K_{t}=T_{t}
$$

A competitive equilibrium with taxes $\left\{\left\{\tau_{j t}\right\}_{j=1,2,3}, \tau_{t}^{k}, T_{t}\right\}_{t=0}^{\infty}$ is a sequence of allocations $\left\{C_{t}, N_{0 t}, N_{2 t}, N_{3 t}, R_{t}, K_{t}, S_{t}\right\}_{t=0}^{\infty}$ and prices $\left\{q_{t}^{0},\left\{p_{j t}\right\}_{j=1,2,3}, w_{t}, r_{t},\right\}_{t=0}^{\infty}$ such that: (i) given taxes and prices, the allocation solves the consumer's problem by maximizing (8) subject to (28), and the firms' problem by maximizing $\Pi_{0}$ and $\Pi_{j}$ for $j=1,2,3$; (ii) given the allocation, transfers are such that the government budget constraint (29) is satisfied; (iii) given the allocation, the carbon cycle follows (6); and (iv) prices clear the markets.

The optimal energy taxes come from comparing the optimal allocation with the competitive equilibrium. As a benchmark case, it is useful to think about the optimal policy when the social and private discount rates are the same. In this case, it is easy to show that the optimal policy is to set carbon taxes on oil and coal equal to the social cost of carbon, while the optimal subsidies on green energy and capital income are zero. The literature often refers to these tax rates as "Pigouvian taxes" because they are meant to correct an externality. With these carbon taxes, energy firms face the social cost of their production and, as a consequence, they produce the optimal amount. Because, by definition, the green sector does not involve any externality, the subsidy on green energy is zero. Some models incorporate learning-by-doing in the renewable industry. In these models, productivity increases the more renewable energy is produced. When this process includes learning externalities, then a rationale for green subsidies arise. On the contrary, this paper considers that the technological change in the renewable sector is exogenous. Therefore, the optimal renewable subsidies are zero. Optimal capital income subsidies are also zero because the investment decision should remain undistorted according to equation (21). 
In a broader sense, Pigouvian taxes are taxes designed to correct any discrepancy between the market outcome and the socially optimal outcome. When the social and private discount rates differ, the market economy saves too little when evaluated from a societal point of view. In this economy, this means not only a low accumulation of capital but also a fast depletion of the exhaustible resource. It follows that the optimal carbon taxes will pick up this "discrepancy", and the tax rates may differ from the Pigouvian ones described above ${ }^{3}$.

The next proposition is the main result of the paper. The uniform taxation principle on all carbon energy inputs breaks in an economy that incorporates social discounting. In particular, the optimal carbon tax on coal is not equal to the optimal carbon tax on oil. This is true even if both had the same effect on the aggregate stock of carbon. Moreover, while the optimal carbon tax on coal remains equal to the social cost of carbon, the optimal tax on oil includes also the private and social discount rates as an extra term in the carbon tax formula. Besides, a capital income subsidy is optimal. Proposition 1 formalizes this result.

Proposition 1 (Optimal Energy Taxes) Suppose that $\left\{C_{t}^{*}, N_{0 t}^{*}, N_{2 t}^{*}, N_{3 t}^{*}, R_{t}^{*}, K_{t}^{*}, S_{t}^{*}\right\}_{t=0}^{\infty}$ solves the social planning problem, then it solves the competitive equilibrium with taxes equal to

$$
\begin{aligned}
\tau_{1 t} & =\left(\frac{\hat{\beta}}{\beta}\right)^{t} \Lambda_{t}^{*}-\left[\left(\frac{\hat{\beta}}{\beta}\right)^{t}-1\right]\left[x\left(S_{t}\right) F_{r}^{\prime}(t)-g^{\prime}\left(R_{t}\right)\right] \\
\tau_{2 t} & =\Lambda_{t}^{*} \\
\tau_{3 t} & =0 \\
\tau_{t}^{k} & =1-\frac{\hat{\beta}}{\beta}
\end{aligned}
$$

for every period $t$ and all proceeds from taxation rebated/financed lump-sum through $T_{t}$.

The optimal energy taxes reflect the climate externality. Oil and coal use increases the stock of carbon in the atmosphere and causes climate damages. Thus, the optimal carbon taxes on coal and oil have the social cost of carbon as a component of the tax formula. The tax rates reflect the climate externality and induce individuals to internalize it in a standard Pigouvian

\footnotetext{
${ }^{3}$ Besides the climate externality, social discounting is the only source of discrepancy between the market outcome and the socially optimal one. In particular, the after-tax market price of energy is efficient, and there are no distortions related to incorrect pricing of energy inputs or corruption in the economy. Adding these features to the energy sector may be appropriate given some of the characteristics of the oil-rich developing economies, although it goes beyond the scope of the paper.
} 
fashion. Green energy, on the other hand, has no effect on the atmospheric carbon level and the optimal renewable subsidy is zero.

It is easy to see that if the social and private discount rates are the same, the optimal carbon tax on coal and oil given by the formulas (30) and (31) are both equal to the social cost of carbon. As discussed in section 4, when the government takes into account the welfare of future generations directly, the social discount rate is lower than the private one. In this case, the policy prescription is that the use of the economy's resources must follow a more patient forward-looking path. This path takes special care of the resources that the current generation passes on to future ones. In this sense, the use of oil reserves is of particular interest because oil is an exhaustible resource. Caring for future generations requires keeping more oil under the crust of the earth, and the optimal oil tax reflects that by adding the ratio of discount rates to the tax formula.

The case of coal is slightly different. The reason is that even though coal is also an exhaustible resource, it is so abundant that it can be considered a resource in infinite supply for practical matters. In particular, the government can rely on the market economy to decide on how much coal to use because the stock of coal will always remain in infinite supply for future generations to use. Thus, the difference between the social and private discount rates does not play a role in designing the optimal coal tax. The reason is not that the difference does not exist but because its effect on the optimal taxation of a resource in infinite supply is insignificant. It is still optimal to introduce a carbon tax on coal equal to the social cost of carbon.

Proposition 1 is an important result because it breaks the equivalence between energy taxes. As showed in Golosov et al. (2014), standard public finance theory prescribes a uniform tax on all carbon energy inputs. This paper shows that the uniform taxation principle does not go through to a setting with social discounting.

The formula for the carbon tax on oil collapses to that in Belfiori (2017) if the production function is linear in oil and separable. As noted in that paper, two effects are playing a role in the optimal carbon tax. First, oil extraction must slow down to account for the climate externality. Second, oil extraction must also slow down to induce individuals to keep more oil reserves for future generations to use. Because oil is an exhaustible resource, a lower extraction path requires a decreasing tax rate. Oil companies have incentives to extract more tomorrow if the return is relatively higher tomorrow. With increasing extraction costs, this is achieved with a decreasing tax rate. Notice that a decreasing oil tax can potentially 
turn into a decreasing subsidy. Importantly, the optimal carbon tax on oil will eventually be lower than the carbon tax on coal.

This paper assumes that coal and oil have the same effect on the aggregate externality. However, coal is, in fact, a dirtier energy source in the sense that emits more $\mathrm{CO}_{2}$ than oil per unit of energy. van der Ploeg and Withagen (2012) shows that, if one takes into account that coal is dirtier, it is optimal to use more oil and less coal. The same result holds in Golosov et al. (2014) who also find that the welfare gains from the introduction of an optimal carbon tax come from the efficient use of coal and not so much of oil. Even though oil is used up too quickly in the laissez-faire economy, the inefficient use of coal leads to substantial welfare losses because the stock of coal is much larger. Thus, both papers argue that coal is the real threat to climate change. To some extent, this result may be overturned when there is social discounting. In particular, the effects of having social discounting act through the use of oil and not coal for the very reason that coal is so abundant. Overall, the welfare gains from introducing a carbon tax that corrects the externality and achieves the targeted intergenerational equity come from the use of oil and not coal. Whether or not this is the case is a quantitative question and an intriguing avenue for future research.

Regarding the capital stock, Proposition 1 shows that a subsidy on capital income is an essential part of any comprehensive climate policy that seeks to achieve intergenerational climate equity. The optimal subsidy is constant over time and equal to the ratio of social to private discount rates. The optimal subsidy is the same as the one found in von Below (2012) and Barrage (2018). Although they work in a different environment, the subsidy rate also equals the optimal subsidy on bequeaths characterized by Farhi and Werning (2010). The intuition for this result is quite simple. As mentioned before, when the government takes into account the welfare of future generations directly, the policy prescription is to do a more patient forward-looking use of the economy's resources taking special care of the resources that the current generation passes on to future ones. A subsidy on capital income induces individuals to invest in capital for future generations to use in the same way that a decreasing tax on oil causes oil companies to keep more oil under the crust of the earth. Both policy instruments imply a reallocation of resources in favor of future generations, which is optimal on the grounds of achieving a given degree of intergenerational climate equity.

Notice also that, given that capital and oil reserves are alternative saving assets and that a capital income subsidy is optimal, it follows that a subsidy on oil in situ may have a role to 
play in the optimal climate policy ${ }^{4}$. Belfiori (2017) shows that an oil stock subsidy is optimal in an economy with social discounting. In that paper, oil is the only asset and energy input in production. Corollary 1 extends this result to an economy with capital and coal and renewables as additional sources of energy. This alternative decentralization of the optimal allocation relies on a subsidy on the stock of oil in situ, uniform carbon taxes on coal and oil, and a subsidy on capital income.

Corollary 1 Suppose that $\left\{C_{t}^{*}, N_{0 t}^{*}, N_{2 t}^{*}, N_{3 t}^{*}, R_{t}^{*}, K_{t}^{*}, S_{t}^{*}\right\}_{t=0}^{\infty}$ solves the social planning problem, then it solves the competitive equilibrium with taxes equal to

$$
\begin{aligned}
\tau_{1 t} & =\tau_{2 t}=\Lambda_{t}^{*} \\
\tau_{3 t} & =0 \\
s_{t}^{E_{1}} & =\left(\frac{\hat{\beta}}{\beta}-1\right)\left[x\left(S_{t}\right) F_{r}^{\prime}(t)-g^{\prime}\left(R_{t}\right)-\Lambda_{t}^{*}\right] \\
\tau_{t}^{k} & =1-\frac{\hat{\beta}}{\beta}
\end{aligned}
$$

for every period $t$ and all proceeds from taxation rebated/financed lump-sum through $T_{t}$.

Under this decentralization, a typical firm in the oil sector faces two types of taxation. On the one hand, the firm pays a carbon tax per unit of $\mathrm{CO}_{2}$ emitted. On the other hand, the firm receives a subsidy proportional to its oil reserves. This subsidy provides an extra incentive to delay extraction and guarantees that future generations will inherit the socially optimal amount of oil reserves.

In a sense, this alternative decentralization isolates the externality part from the intergenerational equity dimension of the climate change problem. Carbon taxes are designed to address the externality, and the subsidies on oil and capital income address the intergenerational equity goal. However, notice that the tax and subsidy rates are a function of the optimal allocation which reflects both the externality and intergenerational equity policy goals. Thus, carbon taxes and oil and capital subsidies are jointly determined and cannot be determined in isolation. Both the externality and the intergenerational equity problem are essential components of the global warming phenomena, and climate policies should be

\footnotetext{
${ }^{4}$ More generally, a low social discount rate will imply that it is optimal to subsidize all forms of capital accumulation in the economy. From education and human capital accumulation to investment in climate adaptation and physical capital, the market economy will be saving and investing less than what is socially optimal.
} 
designed to address both sides of the same coin. Also, it is important to mention that the subsidy on the oil stock is a redundant instrument in the sense that the same outcome is achievable with fewer instruments. If well-designed, carbon taxes are a sufficient tool to obtain the optimal outcome in the market economy. Moreover, the opposite does not hold. Carbon taxes are not redundant because it is not possible to implement the optimal allocation only with a subsidy on oil and capital stocks.

The climate policy in Proposition 1 is equivalent to the one in Corollary 1 in the sense that both implement the socially optimal allocation as an equilibrium outcome. However, the fiscal cost of this alternative policy is of course higher.

\section{Concluding Remarks}

When the British government released the "Stern Review on the Economics of Climate Change", a heated debate arose around the role of social discounting on shaping the climate policy. The underlying disagreement has been on whether or not there is an intergenerational equity problem associated with climate change that policymakers need to take a stand on. Climate change is a long-term problem, and the current generation's emissions will have an impact on the well-being of future ones. The question is whether or not the market takes care on its own of the future generations' welfare once the climate externality is internalized.

The question is normative in essence, and the answer to it differs among policymakers. There are as many answers as politicians around the world. Each country has its own policy agenda that shapes its policy goals. For some, intergenerational climate equity is one of them; for others, it is not. While the intergenerational climate equity goals are a policy choice, the optimal climate policies associated with these goals are not. This paper shows that: (i) A uniform tax on all carbon energy inputs is the optimal policy when no intergenerational climate equity goal enters the policy design problem; (ii) Otherwise, a carbon tax on oil (and gas) different to the carbon tax on coal is the optimal policy. The difference between oil and coal taxes is higher, the higher the future generations' weight on social welfare. According to the British government - as explained in the Stern Review - future generations should have almost equal weight as current generations do in social welfare. The difference in the welfare weights is only to account for the possibility of human extinction. This approach to the climate problem will lead to the biggest divergence between oil and coal carbon taxes. As the weight on future generation's welfare decreases, the divergence shrinks and it disappears 
when no direct weight is attached to future generations' welfare.

Countries also differ on the availability of policy instruments. While some policy-makers are inclined to tax carbon, others are keener on paying subsidies. For example, most countries around the globe have some form of subsidization of renewable energy. This paper also shows that a subsidy on oil and natural gas reserves is an optimal climate policy in countries that incorporate intergenerational climate equity goals in their policy agenda. This subsidy must be combined with a uniform tax on all carbon energy inputs. Again, the subsidy is the highest in the scenario of almost equal weights among generations, and it decreases as the weight on future generation's welfare decreases. The subsidy is not optimal when intergenerational climate equity is not a policy goal.

While countries shape their climate policy agenda around the world, it is essential not to disentangle the discussion between policy goals and policy instruments. When governments decide to seek some form of intergenerational climate justice, they must also put on the table what policies are they going to pursue to achieve them. This paper is a step forward in that direction.

\section{A Mathematical Appendix}

Proof of Proposition 1. The proof consists of showing that all conditions for an equilibrium are satisfied by the optimal allocation when taxes and subsidies are set optimally. A competitive equilibrium is fully characterized by the following system of equations

$$
\begin{aligned}
x\left(S_{t}\right) F_{N_{0}}^{\prime}(t) & =x\left(S_{t}\right) F_{N_{2}}^{\prime}(t)-\tau_{2 t} \\
x\left(S_{t}\right) F_{N_{0}}^{\prime}(t) & =x\left(S_{t}\right) F_{N_{3}}^{\prime}(t) \\
\beta u^{\prime}\left(c_{t+1}\right)\left[x\left(S_{t+1}\right) F_{r}^{\prime}(t+1)-g^{\prime}\left(R_{t+1}\right)-\tau_{1 t+1}\right] & =u^{\prime}\left(c_{t}\right)\left[x\left(S_{t}\right) F_{r}^{\prime}(t)-\tau_{1 t}\right] \\
\beta u^{\prime}\left(c_{t+1}\right)\left(1-\tau_{t+1}^{k}\right) x\left(S_{t+1}\right) F_{k}^{\prime}(t+1) & =u^{\prime}\left(c_{t}\right)
\end{aligned}
$$

together with the feasibility constraints (10)-(11) and the transversality condition for the capital stock. Regarding the green energy sector, it is easy to see that equations (19) and (39) are the same when $\tau_{3 t}$ equals zero. Similarly, equation (18) coincides with equation (38) when $\tau_{2 t}=\Lambda_{t}^{*}$. To see that $\tau_{1 t}$ as defined in the proposition is optimal, plug the tax rate in the inter-temporal condition for oil to get

$$
\frac{\beta u^{\prime}\left(c_{t+1}\right)}{u^{\prime}\left(c_{t}\right)}=\frac{\left[x\left(S_{t}\right) F_{r}^{\prime}(t)-\left(\frac{\hat{\beta}}{\beta}\right)^{t} \Lambda_{t}^{*}+\left[\left(\frac{\hat{\beta}}{\beta}\right)^{t}-1\right]\left(x\left(S_{t}\right) F_{r}^{\prime}(t)-g^{\prime}\left(R_{t}\right)\right)\right]}{\left[x\left(S_{t+1}\right) F_{r}^{\prime}(t+1)-\left(\frac{\hat{\beta}}{\beta}\right)^{t+1} \Lambda_{t+1}^{*}+\left[\left(\frac{\hat{\beta}}{\beta}\right)^{t+1}-1\right]\left(x\left(S_{t+1}\right) F_{r}^{\prime}(t+1)-g^{\prime}\left(R_{t+1}\right)\right)\right]}
$$


After some simple algebra, we obtain

$$
\frac{\beta u^{\prime}\left(c_{t+1}\right)}{u^{\prime}\left(c_{t}\right)}=\frac{\left(\frac{\hat{\beta}}{\beta}\right)^{t}\left[x\left(S_{t}\right) F_{r}^{\prime}(t)-\Lambda_{t}^{*}\right]}{\left(\frac{\hat{\beta}}{\beta}\right)^{t+1}\left[x\left(S_{t+1}\right) F_{r}^{\prime}(t+1)-g^{\prime}\left(R_{t+1}\right)-\Lambda_{t+1}^{*}\right]}
$$

which coincides with (20) after canceling out the ratio of discount factors. Moreover, plug the capital income subsidy rate into (41) in order to get

$$
\beta u^{\prime}\left(c_{t+1}\right)\left(1+\frac{\hat{\beta}}{\beta}-1\right) x\left(S_{t+1}\right) F_{k}^{\prime}(t+1)=u^{\prime}\left(c_{t}\right)
$$

which coincides with (21) after canceling out the private discount factor. The feasibility constraints and transversality conditions are satisfied by definition of the competitive equilibrium. This completes the proof that all conditions for a competitive equilibrium with taxes are satisfied by the optimal allocation.

Proof of Corollary 1. The proof consists of showing that all conditions for an equilibrium are satisfied by the optimal allocation when taxes and subsidies are set optimally. The inter-temporal equilibrium condition for oil extraction is now given by

$$
\beta u^{\prime}\left(c_{t+1}\right)\left[x\left(S_{t+1}\right) F_{r}^{\prime}(t+1)-g^{\prime}\left(R_{t+1}\right)-\tau_{1 t+1}+s_{t+1}^{E_{1}}\right]=u^{\prime}\left(c_{t}\right)\left[x\left(S_{t}\right) F_{r}^{\prime}(t)-\tau_{1 t}\right]
$$

A competitive equilibrium is fully characterized by equations (38)-(39) and (41)-(42) together with the feasibility constraints (10)-(11) and the transversality condition for the capital stock. Following the proof of proposition 1, equations (18) and (38) and equations (19) and (39) are the same when taxes $\tau_{3 t}$ equals zero and $\tau_{2 t}=\Lambda_{t}^{*}$. To see that $\tau_{1 t}$ and $s_{t}^{E_{1}}$ as defined in the proposition are optimal, plug the tax and the subsidy rate in the inter-temporal condition for oil (42) to get

$$
\beta u^{\prime}\left(c_{t+1}\right)\left[x\left(S_{t+1}\right) F_{r}^{\prime}(t+1)-g^{\prime}\left(R_{t+1}\right)-\Lambda_{1 t+1}^{*}\right]\left(1+\frac{\hat{\beta}}{\beta}-1\right)=u^{\prime}\left(c_{t}\right)\left[x\left(S_{t}\right) F_{r}^{\prime}(t)-\Lambda_{1 t}^{*}\right]
$$

which coincides with (20) after canceling out the private discount factor. Moreover, plug the capital income subsidy rate into (41) in order to get

$$
\beta u^{\prime}\left(c_{t+1}\right)\left(1+\frac{\hat{\beta}}{\beta}-1\right) x\left(S_{t+1}\right) F_{k}^{\prime}(t+1)=u^{\prime}\left(c_{t}\right)
$$

which coincides with (21) after canceling out the private discount factor. The feasibility constraints and transversality conditions are satisfied by definition of the competitive equilibrium. This completes the proof that all conditions for a competitive equilibrium with taxes are satisfied by the optimal allocation. 


\section{References}

Acemoglu, D., P. Aghion, L. Bursztyn, and D. Hemous (2012). The environment and directed technical change. American Economic Review 102(1), 131-66.

Barrage, L. (2017). Optimal dynamic carbon taxes in a climate-economy model with distortionary fiscal policy. Forthcoming Review of Economic Studies.

Barrage, L. (2018). Be careful what you calibrate for: Social discounting in general equilibrium. Journal of Public Economics 160, 33 - 49.

Belfiori, M. E. (2015). Time Consistent Climate Policies. In: Political Economy and Instruments of Environmental Politics. CESifo Seminar Series. The MIT Press.

Belfiori, M. E. (2017). Carbon pricing, carbon sequestration and social discounting. European Economic Review 96, 1 - 17.

Bernheim, B. D. (1989). Intergenerational altruism, dynastic equilibria and social welfare. The Review of Economic Studies 56(1), 119-128.

Farhi, E. and I. Werning (2007). Inequality and social discounting. Journal of Political Economy 115(3), 365-402.

Farhi, E. and I. Werning (2010). Progressive estate taxation. The Quarterly Journal of Economics 125(2), 635-673.

Gerlagh, R. and M. Liski (2018). Consistent climate policies. Journal of the European Economic Association 16(1), 1-44.

Golosov, M., J. Hassler, P. Krusell, and A. Tsyvinski (2014). Optimal taxes on fossil fuel in general equilibrium. Econometrica 82(1), 41-88.

Harstad, B. (2012). Buy coal! a case for supply-side environmental policy. Journal of Political Economy 120(1), 77-115.

Karp, L. Provision of a public good with multiple dynasties. The Economic Journal 127(607), 2641-2664.

Nordhaus, W. D. (2007). A review of the "Stern Review on the economics of climate change". Journal of Economic Literature, 686-702. 
Stern, D. I. (2010). Interfuel substitution: A metaanalysis. Journal of Economic Surveys $26(2), 307-331$.

Stern, N. (2008). The economics of climate change. American Economic Review 98(2), 1-37.

Tinbergen, J. (1952). On the theory of economic policy. Contributions to economic analysis. North-Holland.

van der Ploeg, F. and C. Withagen (2012). Too much coal, too little oil. Journal of Public Economics 96(1-2), $62-77$.

von Below, D. (2012). Optimal carbon taxes with social and private discounting.

Weitzman, M. L. (2007). A review of the Stern Review on the economics of climate change. Journal of Economic Literature 45(3), 703-724. 